\title{
Principles of Sustainable Infrastructure Formation in Research and Technology Development Centers Construction
}

\author{
Andrey Pustovgar ${ }^{1,2}$, Vyacheslav Medvedev ${ }^{1, *}$, Aleksey Adamtsevich ${ }^{1}$ and Zdenka J. \\ Popović ${ }^{3}$ \\ ${ }^{1}$ Moscow State University of Civil Engineering, Yaroslavskoe shosse, 26, Moscow, 129337, Russia \\ ${ }^{2}$ Science Center for Nonlinear Wave Mechanics and Technology, Institute of Machine Science, \\ Russian Academy of Sciences, (NTs NVMT IMASh), 4, M. Kharitonyevskiy Pereulok, 101990, \\ Moscow, Russia \\ ${ }^{3}$ University of Belgrade, Faculty of Civil Engineering, Bulevar kralja Aleksandra 73, 11000, \\ Belgrade, Serbia
}

\begin{abstract}
The paper concerns the issue of infrastructure formation in research and technology development centers. It is established that the key point in the design and construction of such centers is providing the effective functioning of social infrastructure, which is a connecting link for the main structural elements of modern research and technology development centers. The grounds for the necessity of working out a unified pattern for designing research and technology development centers in compliance with the urban planning regulations and research and technology development priorities are given. An integrated model for working out a unified pattern of designing research and technology development centers is suggested. This model envisages creating a harmonized international standard that describes the basic principles of sustainable infrastructure formation in research and technology development centers construction. Based on the research results, the principles of sustainable infrastructure formation in research and technology development centers are set out and worded according to the goals of sustainable development. The authors also give grounds for the applicability of the principles formulated in this paper for the infrastructure assessment of research and technology development centers, both operating and under construction, which will make it possible to target the less-developed elements and draw up the plan of their improvement for further sustainable development. The authors also list emerging technologies to be developed and implemented for the efficient accomplishment of the research objectives.
\end{abstract}

* Corresponding author: medvedevvv@mgsu.ru 


\section{Introduction}

Today research and technology development centers are the drivers of advanced technology development that enhance economic stability and strengthen the leadership position of countries in the context of global economy.

The modern world is facing a global tendency of transitioning from industrial, primary export-oriented economy based on primary rent income acquisition and allocation, to the more competitive "economic of innovations", which is based on science-driven technologies and intellectual assets [1-4]. As a result, today the new infrastructure facilities are created worldwide (for instance, territorial commercial clusters, business incubator zones, technology transfer centers, etc.). These centers are geared towards implementation of innovative technologies in the most science-driven spheres of the non-financial economy sector. Such facilities also require an innovative approach to designing their social infrastructure.

Conceptually, all research and technology development centers from the very first ones were created with consideration to the relevant (at that moment) urban planning regulations and global tendencies worldwide. Most of those regulations and tendencies today have either become irrelevant, or have undergone significant changes.

As a rule, all modern research and technology development centers have 5 basic structural components $[5,6]$, combined into a single system (see Fig. 1) which ensures its proper functioning:

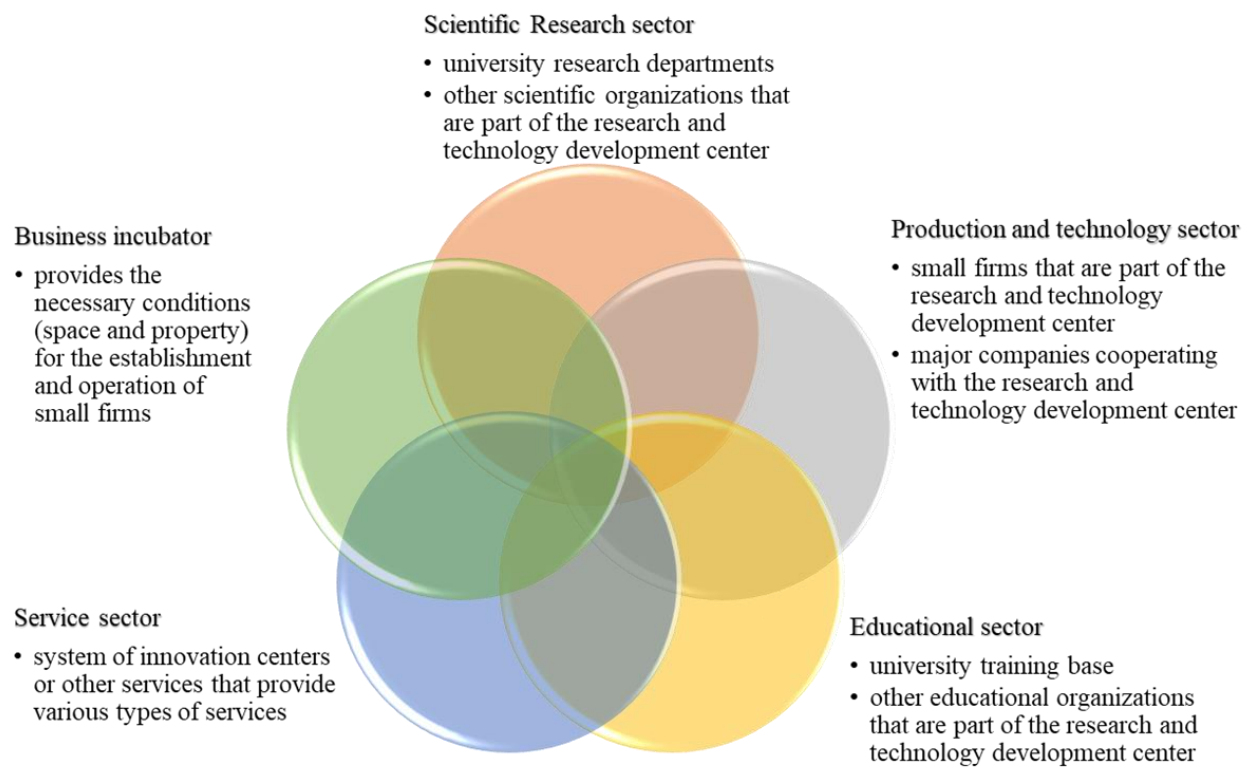

Fig. 1. Basic structural components of modern research and technology development centers

The infrastructure of modern research and technology development centers under formation is designed to provide the scientific community with the most comfortable living conditions to ensure high performance in research, scientific and advanced technological activity and further implementation of the acquired results. The key issue during the design and construction of such centers is the provision of efficient social infrastructure operation, which is a linking point for the 5 basic structural elements of modern research and technology development centers. This can be explained by the absence to this day of a unified pattern for designing research and technology development centers, when each 
individual country has their own set of urban planning regulations and priorities of scientific and technological development.

The modern research and technology development centers may be provisionally grouped according to three patterns - American (USA, UK), Japanese (Japan) and hybrid or European (France, Federal Republic of Germany) [5-8].

The American pattern is focused at the needs of small high-tech business enterprises. These centers are created to form the economic environment capable of insuring further development of research and technology and industrial business activity; to initiate the creation of new small and medium business enterprises; to develop and produce innovative technological products, and, most importantly, to create connections between science and industry. Among the infrastructural peculiarities of the pattern is that in most cases the idea to establish such centers is initiated by the leading educational institution.

The Japanese pattern, unlike the American one, presupposes the construction of entirely new cities - technopolises, where the scientific organizations (that provide research in the leading economy sectors) and industrial centers (that implement the industrial innovations), are localized. The "core" of the majority of existing technopolises (Hiroshima, Ube, Kagoshima) are research towns. The social infrastructure of such technopolises is designed with consideration to the local urban planning regulations and is equipped with a complete set of scientific and industrial complexes, universities and research institutions as well as convenient neighborhoods with cultural and recreational infrastructures. Moreover, Japanese technopolises have a requirement of being built in scenically attractive areas and to be in harmony with the local traditions and natural environment.

The research and technology development centers of the hybrid (European) pattern were formed by borrowing the American and Japanese experience, but with their own special features. The formation participants of such centers are universities, banks, private business enterprises and (only to a certain extent) the government. Their social infrastructure is usually designed with consideration to the regional peculiarities and is geared to provide a highest academic level of the conducted research.

Taking into account the continuously changing global tendencies and priorities of scientific research and high mobility of scientific personnel, there is a pressing need to create a unified pattern for the infrastructure designing of modern research and technology development centers. One of the possible ways to implement this pattern can be the development of a harmonized international standard, where the basic principles of sustainable infrastructure formation will be stipulated. This said, to ensure that this standard relates not only with the national specifics, but also with the worldwide trends that will stay relevant for the decades to come, it is deemed expedient to formulate the principles on the basis of the Sustainable Development Goals, adopted within the UN Sustainable Development Agenda.

The UN Sustainable Development Agenda was developed and adopted in 1992 at the UN conference in Rio de Janeiro. It was formed by merging of three main directions: economic, social and environmental. In 2015 within the Agenda there were developed and adopted 17 new Sustainable Development Goals (Fig. 2) [9]. 


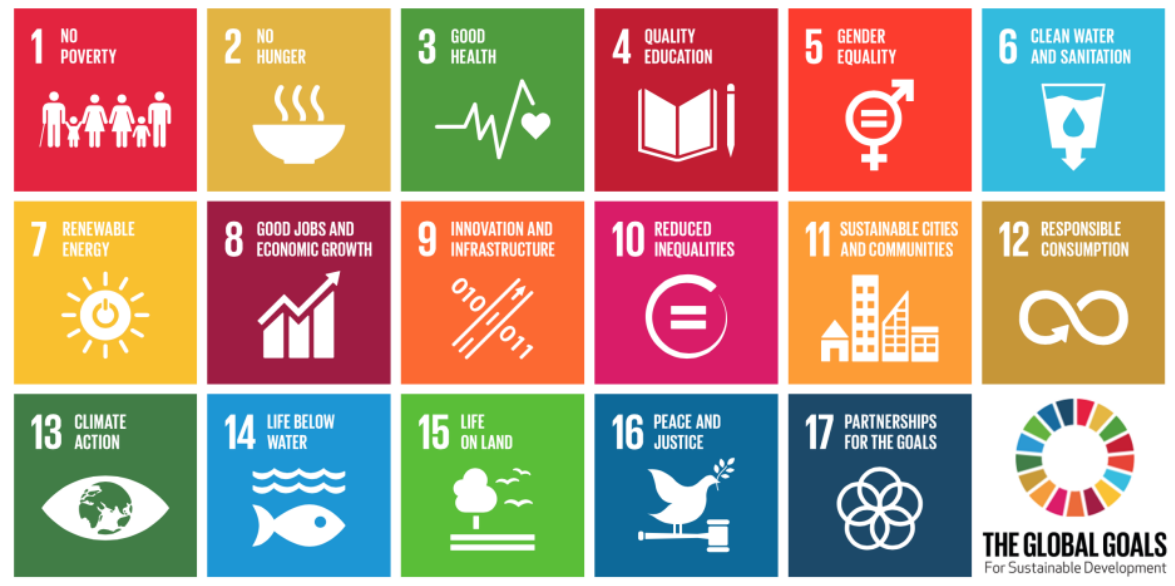

Fig. 2. Sustainable Development Goals

As of this day, the Agenda is widely spread around the world and is often referred to as the "global agenda for the future of civilization". The Sustainable Development Goals are used as a reference point when drafting government programs and other strategic documents that secure the proper fulfillment by each UN member country of their international obligations.

The implementation of these Goals for creating the principles of the formation of sustainable research and technology development centers infrastructure within the harmonized international standard will allow securing its relevance for the national contexts of different countries and further developing of a unified pattern for the performance efficiency assessment in both new and operating research and technology development centers.

\section{Principles of Sustainable Infrastructure Formation}

The analysis of the worldwide practices of leading research and technology development centers construction [2-8, 10-18] allows to conclude that the process of their establishment was triggered by economic crises, especially during the first years of their operation. This can be explained by the fact that it is in the times of crisis when there is a need for radically new solutions in the area of resource-saving technologies development and new competitive products. Moreover, the issues of unemployment and science professionals outflow come to be pressing. The driving force for mitigating the crisis is providing support for the new scientific research and innovation, which results in new quotable jobs, improvement or establishment of a favorable social infrastructure.

In point of fact, successful establishment and operation of all research and technology development centers is based on one general principle: the formation of advanced infrastructure that provides opportunities for rapid innovations implementation and naturally creates within itself a mutually beneficial "science-industry" interaction environment.

It is therefore deemed appropriate to formulate the general principles of sustainable infrastructure formation in relation to research and technology development centers with consideration to successful attainment of the following Sustainable Development Goals:

- No poverty (Goal No. 1)

- Zero hunger (Goal No. 2)

- Good Health and Well-Being (Goal No. 3) 
- Quality Education (Goal No. 4)

- Clean Water and Sanitation (Goal No. 6)

- Affordable and Clean Energy (Goal No. 7)

- Decent Work and Economic Growth (Goal No. 8)

- Industry, Innovation and Infrastructure (Goal No. 9)

- Sustainable Cities and Communities (Goal No. 11)

- Responsible Consumption and Production (Goal No. 12)

- Climate Action (Goal No. 13)

- Life Below Water (Goal No. 14)

- Life On Land (Goal No. 15)

- Partnerships for the Goals (Goal No. 17)

The analysis of the Goals above helps to lay down two groups of principles: primary (global) and secondary (see Fig. 3).

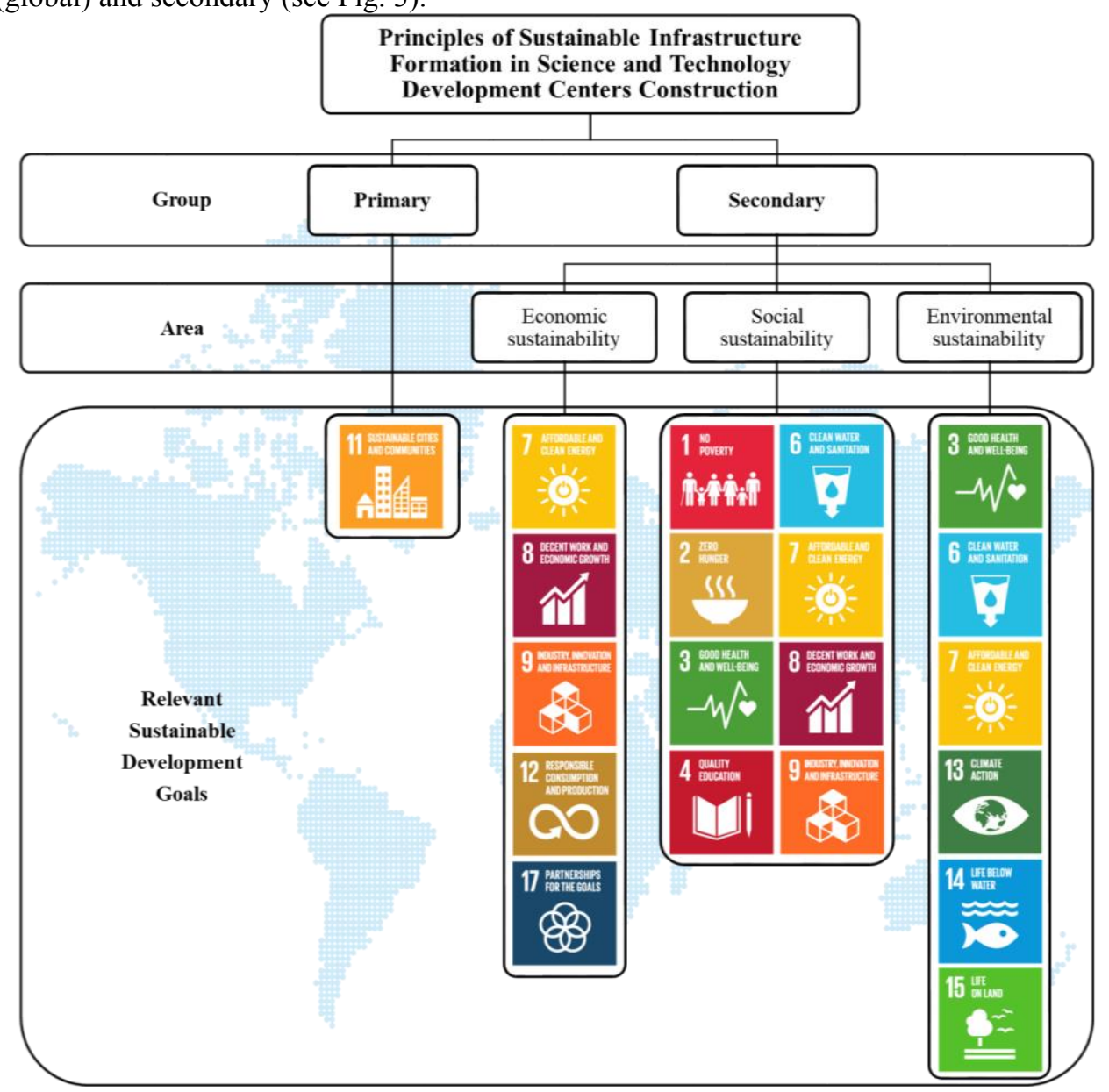

Fig. 3. Suggested groups of principles of sustainable infrastructure formation.

\subsection{Primary Principles}

It is stated that the basic and overarching principle of sustainable infrastructure formation in research and technology development centers in the proposed pattern is meant to be the 
level of attainability of Goal No. 11 "Sustainable Cities and Communities". This goal characterizes the general degree of integration and interconnection of all other (secondary) principles into the design of the infrastructure of a research and technology development center (Fig. 4). Present-day practices $[6,13]$ show that infrastructure formation in modern research and technology development centers is a comprehensive process, which takes into account the urban planning policy regulations of each individual country. This being said, there does not exist a unified pattern for the development of comprehensive system of infrastructural assets for such centers. This tendency may lead to some key elements of the system falling out. For instance, the absence of a unified interaction environment for the engineering and transport systems may lead to public transportation inefficiency even if each individual system generally complies with the adopted Sustainable Development Goal.

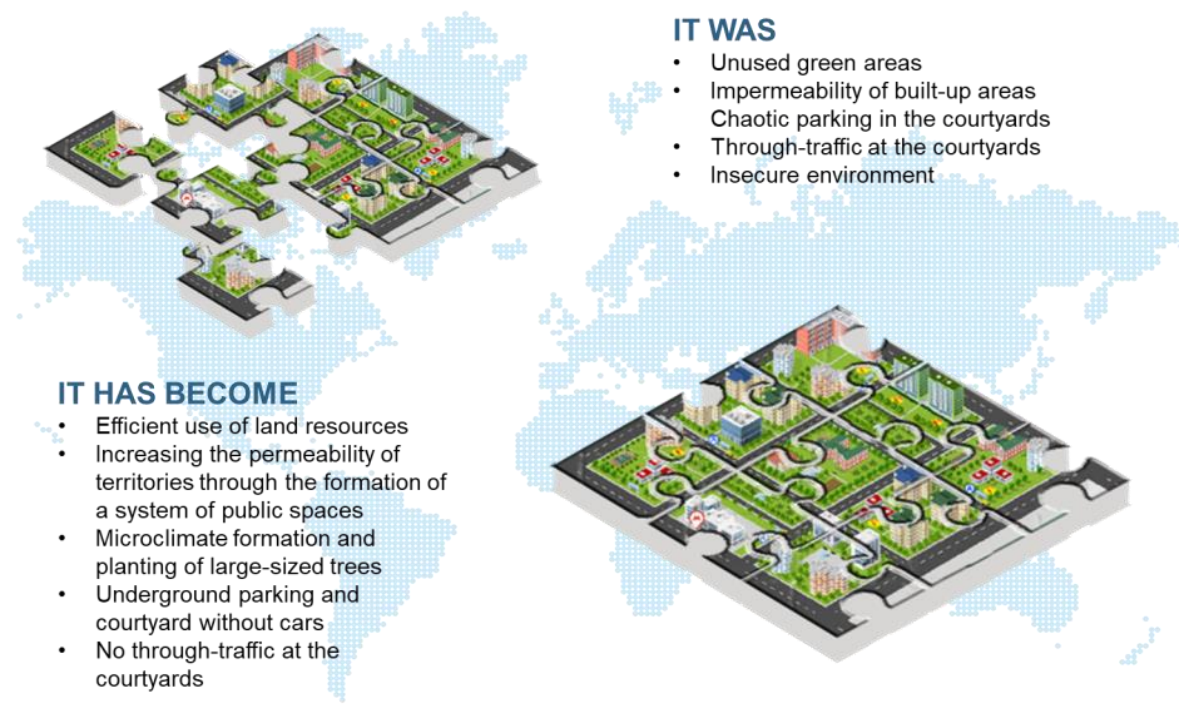

Fig. 4. Sustainable Development Goals integration in designing new research and technology development centers

\subsection{Secondary Principles}

To facilitate the Primary Principle implementation, 3 areas were highlighted:

- Economic Sustainability

- Social Sustainability

- Environmental Sustainability

The construction of the infrastructure assets stated below as well as actions taken in these areas will facilitate the formation of efficient sustainable infrastructure of research and technology development centers.

\subsubsection{Economic Sustainability}

A research and technology development center can be considered economically sustainable if within the formed infrastructure it is possible to maintain continuous, steadfast and effective provision of resources for the development and implementation of innovative products with minimum overhead costs at each stage of core operations. 
The economic sustainability is determined by the presence of the following basic infrastructure assets:

- power-efficient buildings and residential infrastructure assets that lower the center's general energy intensity;

- groups of engineering infrastructure facilities (including power supply systems, water supply and drainage, ventilation, outdoor illumination and communication system) that facilitate efficient performance of companies, production industry and nonproductive sphere assets;

- power engineering facilities for the energy generation using renewable sources.

To facilitate sustainable development and functioning of such assets it is necessary to work out ergonomic systems of engineering infrastructure assets management, global city line monitoring systems and the unified digital environment for both engineering and transport systems [14-16].

The development of the transport system, in turn, will greatly influence the development of international relations. The creation of international platforms for interaction between the participants of the research and technology development center and the development of international relations is one of the fundamental conditions to ensure economic sustainability.

The assessment of economic sustainability over the course of further research will require developing a separate scoring system, which will include the following indicators:

- total number of jobs

- total number of the unemployed

- household income

- household self-sufficiency rate

- total venture capital

- energy production volumes

- energy consumption volumes

- total number of advanced degrees staff

- total number of foreign staff

- number of registered patents

- number of scientific organizations

- volume of scientific research financing

- innovative industries revenue

- etc.

\subsubsection{Social Sustainability}

Social sustainability presupposes active engagement of households in the life of the research and technology development centers, as well as facilitation of continuous growth in household well-being and level of social security.

Social sustainability may be enhanced by the construction of the following facilities:

- affordable buildings and residential infrastructure assets

- sports facilities

- medical centers

- advanced educational institutions

- establishment of recreation and social integration areas

Further development of the social sustainability principle necessitates:

- developing intelligent interaction systems to provide timely and emergency medical care; 
- developing intelligent transportation system capable of adapting to the infrastructure changes;

- creation of quotable jobs by inviting various businesses to join the center;

- making the social infrastructure assets easily available for the public;

- making various services and tools easily available for the public, optimizing the services and tools to meet the needs of the public;

- developing intelligent education systems and the unified digital environment "student - teacher - professional".

Limited or no access to environmentally compatible, reliable and relatively inexpensive energy sources hinders human development as well as social and economic progress of research and technology development center in general $[5,14,15]$.

It is proposed to assess social sustainability according to the following key quantitative indicators:

- availability of new accommodation for purchase

- availability of renting accommodation

- total number of the homeless

- residential development volumes (including those required for providing accommodation in the context of population growth)

- population density

- high school graduation and dropout rate

- industrial construction volumes

- total traffic jam stretch

- average home-to-work travel time

- number of transfers

- total bicycle track length

- proportion of population lacking foodstuffs

- added value per one employee

- dynamic patterns of population

\subsubsection{Environmental Sustainability}

The following assets are necessary for the formation of environmentally sustainable infrastructure:

- available green spaces;

- advanced technology wastewater treatment facilities, primarily near the industrial sites located at the coastal areas;

- residential infrastructure assets built with modern ecologically friendly and resourcesaving technologies and materials

Other factors to enhance environmental sustainability:

- developing management and monitoring systems for the ecological state of nearby maritime and rive zones;

- implementing recycling and reutilization technologies for construction materials;

- securing energy efficiency of the various components of urban infrastructure and their resilience to anthropogenic hazards;

- building sanitary protection areas near industrial facilities to reduce man-made burden;

- environmental management and preservation of existing ecosystems.

Therefore, the quantitative indicators for the assessment of environmental sustainability should be defined by the following: 
- volumes of buildings and residential infrastructure assets construction around larger transportation routes

- volume of recycled water

- generated solar power volume

- proportion of solar power in the total energy use

- air quality assessment by the number of days with ozone concentration levels within the normal range

- availability of electrically operated public transport

- the time necessary to get the approval for the installation of new renewable sources energy generators

- volumes of construction materials recycling

\section{Application of the Principles to assess the conditions of operating research and technology development centers}

For the verification of the suggested principles of sustainable infrastructure formation in research and technology development centers construction it is deemed expedient to assess on the basis of such principles the infrastructure of operating research and technology development centers. In particular, the availability of the secondary principles and related infrastructure assets indicates the degree of sustainable development of such centers, and, in the case of the designed centers, - the possibility of assessing project feasibility from the standpoint of compliance with the global challenges and tendencies.

In illustration of the above, we shall assess the infrastructure of one of the world's oldest research and technology development centers, "Silicon Valley" (USA, California).

As of this day, the center possesses all necessary infrastructure facilities in compliance with the proposed principles. According to the statistics from the open sources [19], there is annual reduction in energy consumption, environmental setting improvement accompanied with total employed population growth. From the social standpoint - the needs of the population are met by way of active inviting of new businesses with a variety of available revenue areas. Further analysis according to the suggested principles shows that this research and technology park displays a comprehensive interconnected developing infrastructure compatible with the requirements for safety and environmental friendliness. In view of the above, it is possible to conclude that this research and technology development center has sustainable infrastructure.

Another approach to analysis may be illustrated by the following observation: this day in Russia there are many "Science Towns" - research and technology development centers founded in the times of USSR with key features of being isolated and targeted at a specific area (as they were founded on the basis of one or several town-forming industrial plants) $[10,20]$. The analysis of their infrastructure with regard to the proposed principles leads to the following conclusions: though these towns were designed and constructed in compliance with the urban planning regulations of that time that can be considered outdated today, the basic infrastructure assets that can facilitate sustainable development are present, but are on the downward path. In this regard, the majority of such Science Towns are incapable of providing comfortable living conditions for the people in line with modern tendencies, which leads to science professionals outflow. Bringing the existing social infrastructure of the Science Towns to compliance with the modern principles of sustainable development will facilitate re-establishment of their academic and technical potential. This approach can be considered expedient with regard to allocated efficiency. 


\section{Conclusions}

In the context of modern day intensification of scientific and technical development the task of developing the infrastructure of the research and technology development centers in terms of the urban planning regulations, design and space-planning solutions for social and residential infrastructure assets, is of great relevance. Such infrastructure enhances target development mobility for the participants in scientific and technical development and promotes efficient implementation of large-scale research projects, including those implemented within multinational collaborations. To be sure, a lot of social and still more residential infrastructure projects for a number of research and technology development centers often fall short of meeting the high requirements for scientific and technical development. This leads to misallocation of human resources. Improving the living conditions, particularly but not exclusively by way of urban environment "revitalizing", often amounts to no more than standard land improvement of the site based on outdated urban planning methods and tools, which were developed with no consideration to the contemporary scientific-and-technological advance data or targets and goals of innovative academic and technological development. Regional and land-use urban planning strategies display passivity of urban planning solutions and no evidence of a comprehensive approach towards their development on the basis of innovative technology, technical and programming tools. Thus, many countries today, including Russia, still have not worked out a comprehensive scientific and technological approach to form up-to-date social and residential infrastructure that will provide target mobility of the participants in scientific and technical development.

The actions presently taken to form residential infrastructure, as a rule, do not envisage employing the full-scale potential of modern materials, technologies and digital platforms. This results in a failure to provide effective technical solutions on such criteria as cost effectiveness, environmental friendliness, energy efficiency, etc. Because of incompatibility between social, public and residential infrastructure designs in research and technology development centers, the time and finances are invested unfeasibly, which adversely affects the performance of the participants in scientific and technical development.

To find a solution to the challenges mentioned above, this research undertakes a comprehensive analysis of best national and global practices in the sphere of design, construction and operation of research and technology development centers to identify a sweeping approach to sustainable infrastructure formation in research and technology development centers.

The results of this research show that sustainable infrastructure formation in new research and technology development centers is conditional upon the principles of urban infrastructure planning at the early stages. This, in turn, presupposes establishing a comprehensive interconnected system of specific infrastructure assets in various areas.

The authors share the opinion that initiating the drawing up of a harmonized international standard for the sustainable infrastructure formation in research and technology development centers based on the UN Sustainable Development Goals will create a standardized document with due consideration to the interests of various countries. Further application of the principles formulated in this paper for the infrastructure assessment of new and operating research and technology development centers will help identify the less developed areas and set out an effective improvement plan for the purposes of sustainable development.

Full compliance of modern research and technology development centers infrastructure with the principles proposed on the basis of Sustainable Development Goals will be the evidence of the efficiency of their infrastructure and its further sustainable development. For this reason, within the framework of this research it is planned to undertake additional 
assessment of the implementation perspectives for selected advanced technologies and best practices to meet the demands of a set social group. Such assessment is planned to involve in-depth studies of urban planning regulations, as well as architectural, engineering, technical and economic aspects of innovative social and residential infrastructure formation to facilitate target mobility of the participants in scientific and technical development.

The advanced technologies in this area include:

- digital design and construction of terraced houses;

- visual and digital infrastructure of townships, including outdoor illumination, local lighting and intelligent outdoor illumination systems;

- parking and security systems for conventional transportation;

- efficient drive-through isles and pavements construction, construction of auxiliary engineering and digital infrastructure customized for unmanned vehicles;

- ornamental plants and engineering systems of their sustainment;

- ecologically and economically efficient systems of individual and collective energy supply;

- ecologically and economically efficient technologies of collection and disposal of consumption waste;

- architectural solutions, including the profile, architectural, urban planning and construction solutions for dynamic ecological settlements;

- cost effective functional spacing and urban planning;

- etc.

This work was financially supported by the Ministry of Science and Higher Education (State task \#7.13284.2018/12.1). All tests were carried out using research equipment of The Head Regional Shared Research Facilities of the Moscow State University of Civil Engineering.

\section{References}

1. L.A. Kormishkina, E.D. Kormishkin, D.A. Koloskov, Journal of Applied Economic Sciences, 11/6, 1114 (2016)

2. Y. Fu, R.A.W. Kok, B. Dankbaar, P.E.M. Ligthart, A.C.R. van Riel, Journal of Cleaner Production, 205, 226 (2018)

3. V. Jegatheesan, J.L. Liow, L. Shu, S.H. Kim, C. Visvanathan, Journal of Cleaner Production, 17/7, 637 (2009)

4. M.V. Nikolaev, K.R. Saubanov, Journal of Economics and Economic Education Research, 17/4, 75 (2016)

5. M. Žižka, V. Hovorková Valentová, N. Pelloneová, E. Štichhauerová, Entrepreneurship and Sustainability Issues, 5/4, 780 (2018)

6. M.E. Porter, Economic Development Quarterly, 14/1, 15 (2000)

7. A. Karaev, S.C.L. Koh, L.T. Szamosi, Journal of Manufacturing Technology Management, 18/7, 818 (2007)

8. P. De Berranger, M.C.R. Meldrum, Urban Studies, 37/10, 1827 (2000)

9. https://www.un.org/sustainabledevelopment/

10. G.M. Kostyunina, V.I. Baronov, MGIMO Review of International Relations, 3/24, 38 (2012)

11. S. Foghani, B. Mahadi, R. Omar, SAGE Open, 7/1, (2017)

12. A. Malakauskaite, V. Navickas, Engineering Economics, 22/1, 50 (2011) 
13. A.V. Fomina, O.N. Berduygina, A.A. Shatsky, Entrepreneurship and Sustainability Issues, 5/3, 467 (2018)

14. Y. Mishenin, I. Koblianska, V. Medvid, Y. Maistrenko, Entrepreneurship and Sustainability Issues, 6/1, 329 (2018)

15. G. Cainelli, A. D'Amato, M. Mazzanti, Resource and Energy Economics, 39, 53 (2015)

16. P. Dewick, M. Miozzo, Futures, 34/9-10, 823 (2002)

17. G. Tuccio, P., Bua, G., Teodoro, F. Failla, V.A. Giuffrida, Procedia Environmental Science, Engineering and Management, 4/3, 191 (2017)

18. R. Adams, S. Jeanrenaud, J. Bessant, D. Denyer, P. Overy, International Journal of Management Reviews, 18/2, 180 (2016)

19. https://siliconvalleyindicators.org/

20. S.S. Nosova, I.D. Mackulyak, S.V. Lyubimtseva, P.F. Askerov, L.I. Shkalaberda, U.T. Aliev, International Review of Management and Marketing, 6/6, 21 (2016) 